\title{
Additive Manufactured Carbon Nanotube/Epoxy Nanocomposites for Heavy-Duty Applications
}

\author{
Qixiang Jiang,*," Haiguang Zhang," Dmitrii Rusakov, Neptun Yousefi, and Alexander Bismarck*
}

Cite This: ACS Appl. Polym. Mater. 2021, 3, 93-97

Read Online

ABSTRACT: A solid epoxy resin formulation containing 2.5 wt $\%$ carbon nanotubes is $3 \mathrm{D}$ printed into self-standing parts, which after thermal curing result in CNTs/epoxy nanocomposites with mechanical properties attractive for heavy-duty applications.

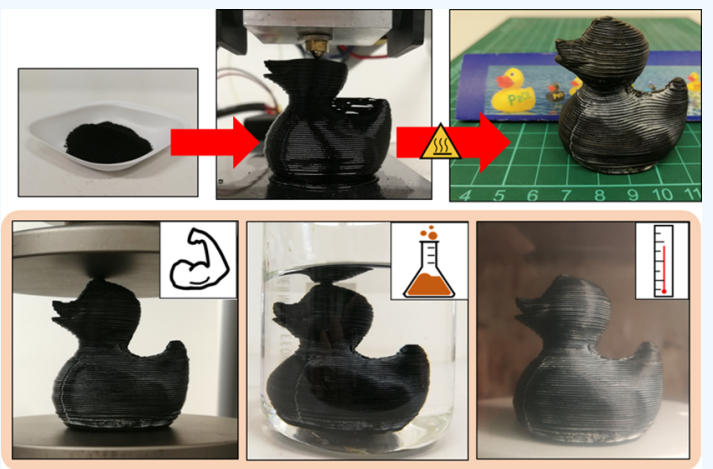

KEYWORDS: solid epoxy, additive manufacturing, fused deposition modeling, composites, direct powder extrusion

\begin{abstract}
A d dditive manufacturing, also known as $3 \mathrm{D}$ printing, is a process where materials are joined layer-by-layer, guided by $3 \mathrm{D}$ model data, to produce complex objects. ${ }^{1}$ Additive manufacturing is advantageous over conventional casting and subtractive methods because of low material wastage and high flexibility allowing for prototyping of complex shaped parts. Since its first commercialization in 1990, fused deposition modeling (FDM) has become the most used 3D printing process due to its simple machine design and low cost. ${ }^{3}$ FDM showed great industrial potential to produce parts for practical applications in medical devices, ${ }^{4}$ heavy-duty parts, ${ }^{5}$ and vehicles. $^{6}$ A wide range of thermoplastic polymers can be used in FDM, ranging from polylactic acid (PLA), to poly(acrylonitrile-co-butadiene-co-styrene) (ABS), to high performance polymers, such as polyether ether ketone (PEEK). ${ }^{7}$ Furthermore, polymers containing metals, ${ }^{8}$ ceramics, ${ }^{9}$ and carbon nanotubes $(\mathrm{CNTs})^{10}$ as fillers and/or reinforcements have been used in FDM to produce composite parts with enhanced stiffness. However, FDM parts exhibit anisotropic mechanical properties, characterized by different properties of the printed parts in a direction perpendicular and parallel to the layer deposition. ${ }^{11}$ This is caused by the presence of interlayers, which possess mechanical properties different from those of each layer of material. ${ }^{12}$ The most used solutions to reduce anisotropy in FDM parts included posttreatments, such as post-layer-fusion, ${ }^{13}$ radiation induced cross-linking of layers, ${ }^{14}$ and polymer infiltration to lock the layers. ${ }^{15}$ On the other hand, since the majority of raw materials for FDM are thermoplastic polymers, the chemical and thermal resistance of the resulting parts is poor (with exception of high
\end{abstract}

performance polymers). These properties limit the applicability of FDM parts for heavy-duty applications, which require stiffness and inertness to be useful in harsh conditions.

We propose to address the above challenges by printing thermosetting resins, which can be cured to produce duromer (i.e., cross-linked) parts. A covalently cross-linked polymer network is anticipated to form throughout the parts (existing in both inner- and interlayers), thus reducing the materials' anisotropy. Furthermore, the cross-linked polymer network provides enhanced solvent and thermal resistance. Compton et al. ${ }^{16}$ developed short fiber-in-epoxy inks; 3D printing and subsequent curing of the inks resulted in bioinspired wood mimics. Pierson et al. ${ }^{17}$ printed (by direct writing) epoxy with chopped carbon fibers. The resulting cured composites had a low void content as well as highly orientated fibers, resulting in a tensile modulus close to the theoretical values. Indeed, the liquid nature of epoxy resin inks promoted fusion between liquid layers as they merged together. However, liquid inks must have a sufficiently high zero-shear viscosity ${ }^{18}$ (solid-like behavior) to allow printing complex structures, as otherwise, the ink would flow apart. Nevertheless, using viscous liquid epoxy or filler-in-epoxy inks still restricts the height of the FDM parts, as the increasing part weight will cause the non-

Received: September 14, 2020

Accepted: December 2, 2020

Published: December 8, 2020 
cross-linked inks to flow. Using solid epoxy resin to address the problem of insufficient zero-shear viscosity of as-printed parts has rarely been reported. Ming et al. ${ }^{19}$ utilized a solid epoxy resin, which melted at an elevated temperature to impregnate continuous carbon fibers. After being printed, the epoxy-resinimpregnated carbon fibers solidified and supported parts for subsequent curing. ${ }^{19}$ Nevertheless, the authors printed and cured only carbon fiber reinforced epoxy parts to a height of 10 $\mathrm{mm}$.

We aim to produce rigid, solvent resistant thermoset CNT/ epoxy nanocomposite parts for applications at harsh conditions. To allow printing of large objects, a solid epoxy resin formulation was used. Solid epoxy resin (with an uncured glass transition temperature of $35{ }^{\circ} \mathrm{C}$ ), latent hardener, accelerator, and 2.5 wt \% CNTs were blended at $62{ }^{\circ} \mathrm{C}$ in a Brabender mixer. After mixing and cooling to room temperature, the formulation solidified and was ground into powder. In a preliminary experiment, the resin powder was transferred into a syringe fitted with a needle of an inner diameter of 1.6 $\mathrm{mm}$. The syringe was attached to a $3 \mathrm{D}$ printing platform (Printrbot Simple Bro base model) (Figure 1a). The syringe

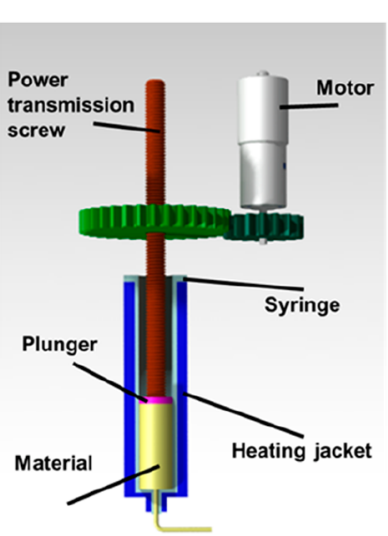

a.

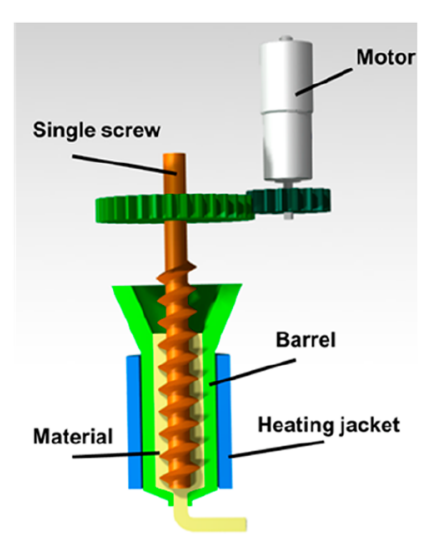

b.
Figure 1. Design of the FDM printer using syringe and plunger (a) and single screw extruder (b). Design a was used to print cubic and rectangular CNT/epoxy composites for compression and flexural tests, while that in $\mathrm{b}$ was used to print dog-bone-shaped composites for tensile tests.

and needle were heated to $77^{\circ} \mathrm{C}$, at which point the resin containing 2.5 wt \% CNTs melted with a complex viscosity of $3000 \mathrm{~Pa}$ s measured at a shear frequency of $2 \mathrm{~Hz}$ (as compared to $2300 \mathrm{~Pa} \mathrm{~s}$ for the resin formulation without CNTs). A motor drove the plunger of the syringe to press the molten resin through the nozzle to print cubes $(15 \mathrm{~mm} \times 15 \mathrm{~mm} \times 15$ $\mathrm{mm}$ ) and rectangles $(80 \mathrm{~mm} \times 10 \mathrm{~mm} \times 3.8 \mathrm{~mm}$ ) (Supporting Information, Section S1). We found that the CNT loading can be up to $2.5 \mathrm{wt} \%$ with respect to the epoxy resin, while a higher CNT loading (5 wt \%) led to a very viscous (14500 Pa s) and uneven flow at $77{ }^{\circ} \mathrm{C}$. Once extruded through the needle, the resin solidified rapidly in air, resulting after printing in uncured yet self-standing objects. To cure the printed objects, they were covered in wet clay, which was dried to form a stiff shell to support the printed parts (a method similar to that reported by Ming et $\mathrm{al}^{20}$ ). The printed parts were then placed into an oven at 50,60 , and $70{ }^{\circ} \mathrm{C}$, respectively, for $24 \mathrm{~h}$. The curing protocol was designed to allow for curing, while avoiding the (wrapped) resin to flow at these temperatures
(Supporting Information, Section S1). After curing at $70{ }^{\circ} \mathrm{C}$, the epoxy resin was postcured at 120 and $150{ }^{\circ} \mathrm{C}$ for $1 \mathrm{~h}$. The absence of a reaction exotherm during differential scanning calorimetry (DSC) (Supporting Information, Figure S4a) confirmed that the objects were fully cured. The glass transition temperature of the nanocomposites was $118{ }^{\circ} \mathrm{C}$ (Supporting Information, Figure S4b).

The bulk and skeletal densities of printed and cured objects were measured using pycnometry on sample pieces and powders, respectively. The printed parts had a bulk and skeletal density of $1.16 \pm 0.01$ and $1.22 \pm 0.01 \mathrm{~g} / \mathrm{cm}^{3}$, respectively, resulting in a void content of $6 \%$. The mechanical properties of the printed and cured objects were measured in compression in the layer-stacking direction ( $Z$ direction) and perpendicular to it ( $X Y$ direction). The elastic modulus and compression strength in the $Z$ direction were $1.3 \pm 0.2 \mathrm{GPa}$ and $81 \pm 3$ $\mathrm{MPa}$, and in the $X Y$ direction, $1.4 \pm 0.1 \mathrm{GPa}$ and $79 \pm 6 \mathrm{MPa}$, respectively. An unpaired two-sample $t$ test confirmed that the properties were identical within error. The rectangular specimens were subjected to flexural tests; they possessed a flexural modulus of $2.0 \pm 0.1 \mathrm{GPa}$ and a strength of $58 \pm 4$ $\mathrm{MPa}$.

The syringe and plunger printer allowed only batch-by-batch printing, limiting the size of the objects to the volume of the raw material in the syringe. Furthermore, the back-pressure increased during extrusion, increasing the power required to drive the plunger. Once the power exceeded the maximum output of the motor, the process ceased, causing materials wastage of up to $50 \%$. Therefore, the $3 \mathrm{D}$ printer was fitted with a single screw extruder (Figure $1 \mathrm{~b}$ ), which was used already for direct extruding/printing polymer pellets ${ }^{21}$ and powder. ${ }^{22} \mathrm{~A}$ nozzle with an inner diameter of $1 \mathrm{~mm}$ was connected to the barrel heated to $80^{\circ} \mathrm{C}$. The molten resin was extruded through the nozzle and was printed into dog bones with a thickness of 3 $\mathrm{mm}$, according to standard EN ISO 527-2 1BA. In each layer of the specimen, a 1-perimeter shell was printed, followed by infilling. The rectangular infills had raster angles of $0^{\circ}, 45^{\circ}$, and $90^{\circ}$ with respect to the length of the objects. The layer thickness was $0.6 \mathrm{~mm}$ (Supporting Information, Section S1). Printed parts were covered with clay and cured as described above.

Printed and cured dog bone specimens consisting of five layers were tensile tested (Supporting Information, Section S1). The tensile loading direction was perpendicular to the printing direction. Specimens with infill raster angles of $0^{\circ}, 45^{\circ}$, and $90^{\circ}$ were tested (Supporting Information, Section S1). All specimens fractured perpendicular to the loading direction rather than followed the interface between printed layers. The spherical voids seen in the fracture surfaces (Figure 2) randomly distributed throughout the nanocomposites and along the interlayer formed by entrapment of air during melting and compaction of the resin powder in the small single screw extruder (Figure 1b) and during printing, i.e., air entrapment between a solidified layer and the next layer being printed. The densities of the printed specimens with infill raster angles of $0^{\circ}, 45^{\circ}$ and $90^{\circ}$, which did include different amounts of interlayers of the infillings, were $1.13 \pm 0.02,1.12$ \pm 0.01 , and $1.10 \pm 0.02 \mathrm{~g} / \mathrm{cm}^{3}$, resulting in a void content of $7 \%, 8 \%$, and $10 \%$, respectively. On the other hand, the CNT/ epoxy composites printed using the FDM with a plunger had a void content of $6 \%$. The larger nozzle diameter allowed for the printing of thicker layers, which resulted in composites with fewer interlayers, and thus voids, per part volume. Without 

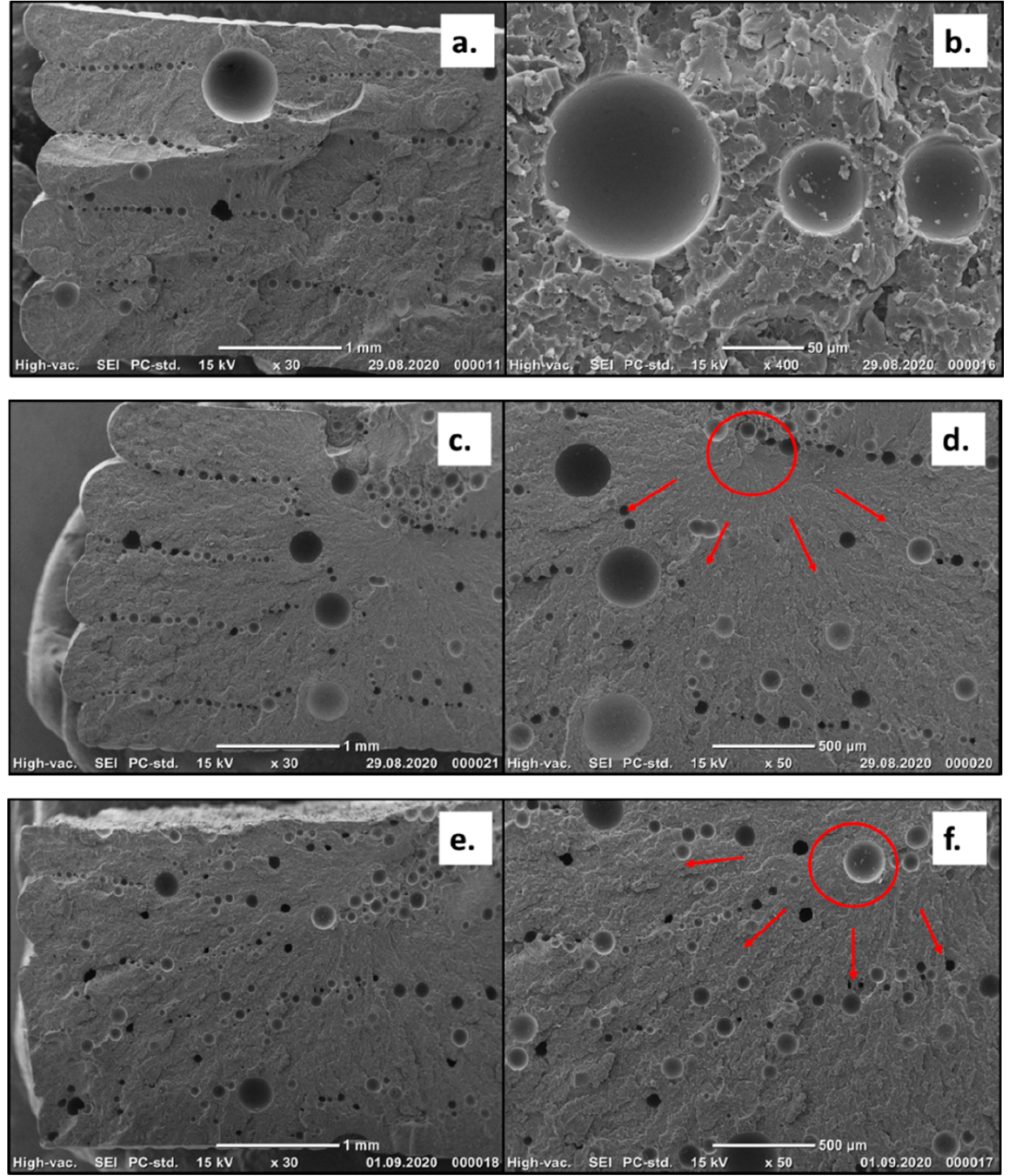

Figure 2. Tensile fracture surfaces of 3D printed CNT/epoxy nanocomposites with infills with raster angles of $0^{\circ}(\mathrm{a}, \mathrm{b}), 45^{\circ}(\mathrm{c}, \mathrm{d})$, and $90^{\circ}(\mathrm{e}, \mathrm{f})$. Red circles show initial cracks formed at void clusters; red arrows indicate crack propagation fronts.
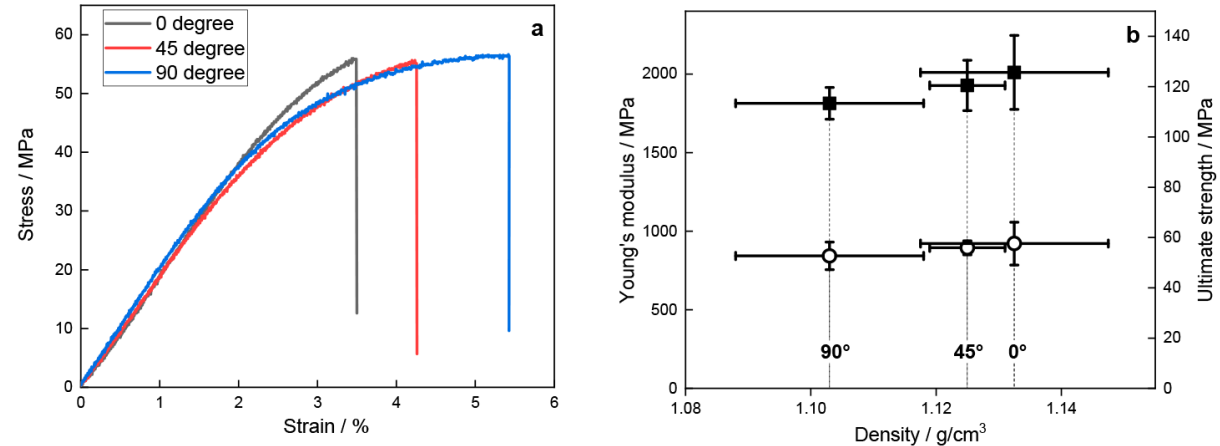

Figure 3. Characteristic tensile stress-strain curves of printed dog bone specimens with raster angles of $0^{\circ}, 45^{\circ}$, and $90^{\circ}$. Young's moduli $(\boldsymbol{\square})$ and ultimate strengths $(\mathrm{O})$ of nanocomposites as a function of bulk density.

vacuum assisted degassing prior to curing, which is typically used to produce void-free polymer composites using conventional composite manufacturing methods, ${ }^{23}$ the voids in $3 \mathrm{D}$ printed CNT/epoxy nanocomposites were difficult to remove. Other than voids, no clear interlayer could be seen (Figure 2b), indicating fused layers in the printed CNT/epoxy nanocomposites. The stress-strain curves were characteristic for stiff but brittle polymers (Figure 3a). From linear regions, the
Young's moduli were determined; specimens with raster angles of $0^{\circ}, 45^{\circ}$, and $90^{\circ}$ had moduli of $2.0 \pm 0.2,1.9 \pm 0.2$, and 1.8 $\pm 0.1 \mathrm{GPa}$. The $0.2 \%$ offset yield of these specimens occurred at strains of $2.2 \pm 0.4 \%, 2.4 \pm 0.4 \%$, and $2.0 \pm 0.4 \%$, resulting in yield strengths of $43 \pm 7,43 \pm 4$, and $38 \pm 5 \mathrm{MPa}$, respectively. The specimens with raster angles of $0^{\circ}, 45^{\circ}$, and $90^{\circ}$ had failure strains of $4.1 \pm 1.2 \%, 4.2 \pm 0.3 \%$, and $4.9 \pm$ $1.0 \%$ with ultimate strengths of $58 \pm 9,56 \pm 3$, and $52 \pm 6$ 
$\mathrm{MPa}$, respectively (Figure $3 \mathrm{~b}$ ). The $\mathrm{CNT} / \mathrm{epoxy}$ nanocomposites had rough fracture surfaces (Figure 2). Figure $2 \mathrm{~d}$ and $f$ show the fracture propagation (red arrows) indicating that the fracture initiated at void clusters in the nanocomposites (red circles). The fracture propagated through the specimens following a radiating pattern but was not governed by interlayer inhomogeneity as reported for $3 \mathrm{D}$ printed PLA ${ }^{12}$ and ABS parts. ${ }^{24}$ This indicated the formation of homogeneous $\mathrm{CNT} /$ epoxy nanocomposites. As such, the cross-linked epoxy network and the incorporation of CNTs rather than the hypothetical anisotropy dominated the mechanical behavior of the $3 \mathrm{D}$ printed nanocomposites. The mechanical properties of our $3 \mathrm{D}$ printed nanocomposites are comparable to literature values of other $3 \mathrm{D}$ printed epoxy composites (Table $\mathrm{S} 1$ in Supporting Information Section S3).

The chemical resistance of the nanocomposites was investigated by immersing them in acetone, isopropanol, dimethylformamide (DMF), tetrahydrofuran (THF), toluene, benzene, (Shell) diesel, dimethyl sulfoxide (DMSO), and 37\% $\mathrm{HCl}$ (experimental details and results are summarized in Supporting Information Section S4). The nanocomposites swelled massively in DMF, THF, and DMSO, leading to sample disintegration within 24,48 , and $48 \mathrm{~h}$, respectively, while acetone caused a volume increase by $30 \%$ in 10 days. The nanocomposites possessed excellent resistance to all other solvents, in which they did not experience any volume change in 10 days.

In previous work on FDM epoxy and epoxy composites using liquid formulations, the printing height was limited. This was caused by the weight of the stacked layers, which deformed previously printed but uncured layers once the load exerted by the part weight exceeded the zero-shear viscosity of the resin. ${ }^{25}$ As a result, the height of printed parts was typically limited to $10 \mathrm{~mm}^{26,27}$ Only some articles reported high printed epoxy parts with dual cured epoxy resin $^{28}$ or fast gelling epoxy formulations. ${ }^{29}$ Solid epoxy resins do allow for overcoming the height limitation; to demonstrate this, we printed and cured a nanocomposite duck (the icon of our group) with a height of $48 \mathrm{~mm}$ (seen in the abstract graphic). The heights of the model and the overhangs show the advantage of solid epoxy formulations for printing large, complex parts. The usefulness of our material for heavy-duty applications was demonstrated using a nanocomposite chain ring connected by two carabineers. The printed ring withstood the load exerted by the weight $(90 \mathrm{~kg}$ ) of a person (Supporting Information Video 1). We also printed a $2.5 \mathrm{~cm}$ tall wrench (spanner) and used it to tighten/loosen a $1 / 4$ in. tube connector at $120{ }^{\circ} \mathrm{C}$ as well as in acetone, respectively (Supporting Information Video 2). These trials demonstrated the usefulness of CNT/epoxy nanocomposites at harsh conditions.

In summary, solid epoxy, hardener, accelerator, and CNTs were melt-blended and subsequently ground; this powder was used as ink for additive manufacturing of nanocomposites. The compression moduli and strengths of the printed nanocomposites were $1.4 \mathrm{GPa}$ and $81 \mathrm{MPa}$, and tensile moduli and strengths, 2.0 GPa and $55 \mathrm{MPa}$, respectively. Even when printed with different raster angles, the nanocomposites had mechanical properties that were identical within error. Fracture surfaces showed that the crack propagation was not governed by the interlayers. This indicated the isotropic mechanical properties of printed nanocomposites in contrast to those of typical FDM polymer materials. These nanocomposites had a glass transition temperature of $118{ }^{\circ} \mathrm{C}$ and exhibited good chemical and thermal resistance, indicating their potential to be used in heavy-duty applications.

\section{ASSOCIATED CONTENT}

\section{Supporting Information}

The Supporting Information is available free of charge at https://pubs.acs.org/doi/10.1021/acsapm.0c01011.

Experimental section, details of the thermal properties of CNT/epoxy composites, comparison of mechanical properties of our printed materials with other printed epoxy composites, and details of the chemical resistance of our printed nanocomposites (PDF)

Video demonstration of a printed composite chain ring (MP4)

Video demonstration of a printed composite wrench (spanner) at elevated temperature and in solvent (MP4)

\section{AUTHOR INFORMATION}

\section{Corresponding Authors}

Qixiang Jiang - Institute of Materials Chemistry and Research, Polymer \& Composite Engineering (PaCE) Group, Faculty of Chemistry, University of Vienna, 1090 Vienna, Austria; ○ orcid.org/0000-0002-4315-2229; Email: qixiang.jiang@ univie.ac.at

Alexander Bismarck - Institute of Materials Chemistry and Research, Polymer \& Composite Engineering ( $\mathrm{PaCE}$ ) Group, Faculty of Chemistry, University of Vienna, 1090 Vienna, Austria; Department of Chemical Engineering, Imperial College London, London SW7 2AZ, United Kingdom; ○ orcid.org/0000-0002-7458-1587;

Email: alexander.bismarck@univie.ac.at

\section{Authors}

Haiguang Zhang - Institute of Materials Chemistry and Research, Polymer \& Composite Engineering (PaCE) Group, Faculty of Chemistry, University of Vienna, 1090 Vienna, Austria; Rapid Manufacturing Engineering Center, School of Mechatronical Engineering and Automation, Shanghai University, Shanghai 200444, China; (1) orcid.org/00000001-9243-1147

Dmitrii Rusakov - Institute of Materials Chemistry and Research, Polymer \& Composite Engineering (PaCE) Group, Faculty of Chemistry, University of Vienna, 1090 Vienna, Austria; (1) orcid.org/0000-0002-2155-4833

Neptun Yousefi - Institute of Materials Chemistry and Research, Polymer \& Composite Engineering (PaCE) Group, Faculty of Chemistry, University of Vienna, 1090 Vienna, Austria; orcid.org/0000-0002-1570-871X

Complete contact information is available at:

https://pubs.acs.org/10.1021/acsapm.0c01011

\section{Author Contributions}

"H.Z. and Q.J. are joint first authors.

\section{Author Contributions}

The following describes the authors' contributions: Q.J., conceptualization, experiments, manuscript drafts and revision; H.Z., experiment, manuscript drafts (H.Z. reconfigured the 3D printer to be used with the single screw extruder, thus enabling printing of CNT/epoxy composites as well as characterization of the composites. H.Z. is credited as a joint first author); D.R., experiments, manuscript drafts; N.Y., preparation of the 
formulation, manuscript revision; A.B., funding acquisition, conceptualization, supervision, manuscript drafts and revisions.

\section{Notes}

The authors declare no competing financial interest.

\section{ACKNOWLEDGMENTS}

We acknowledge funding from the Austrian Science Fund (FWF I1800) for D.R., EU H2020 (760601) for Q.J., UniVie for N.Y., and China Scholarship Council (CSC 201806895016) for H.Z.

\section{REFERENCES}

(1) Wang, X.; Jiang, M.; Zhou, Z.; Gou, J.; Hui, D. 3D printing of polymer matrix composites: A review and prospective. Composites, Part B 2017, 110, 442-458.

(2) Masood, S. H.; Song, W. Q. Development of new metal/polymer materials for rapid tooling using Fused deposition modelling. Mater. Eng. 2004, 25 (7), 587-594.

(3) Weng, Z.; Wang, J.; Senthil, T.; Wu, L. Mechanical and thermal properties of $\mathrm{ABS} / \mathrm{montmorillonite}$ nanocomposites for fused deposition modeling 3D printing. Mater. Des. 2016, 102, 276-283.

(4) Zhao, F.; Li, D.; Jin, Z. Preliminary Investigation of Poly-EtherEther-Ketone Based on Fused Deposition Modeling for Medical Applications. Materials 2018, 11 (2), 288.

(5) Zhang, Y.; Purssell, C.; Mao, K.; Leigh, S. A physical investigation of wear and thermal characteristics of $3 \mathrm{D}$ printed nylon spur gears. Tribol. Int. 2020, 141, 105953.

(6) de Leon, A. C.; Chen, Q.; Palaganas, N. B.; Palaganas, J. O.; Manapat, J.; Advincula, R. C. High performance polymer nanocomposites for additive manufacturing applications. React. Funct. Polym. 2016, 103, 141-155.

(7) Vaezi, M.; Yang, S. Extrusion-based additive manufacturing of PEEK for biomedical applications. Virtual and Physical Prototyping 2015, 10 (3), 123-135.

(8) Liu, Z.; Lei, Q.; Xing, S. Mechanical characteristics of wood, ceramic, metal and carbon fiber-based PLA composites fabricated by FDM. J. Mater. Res. Technol. 2019, 8 (5), 3741-3751.

(9) Taboas, J. M.; Maddox, R. D.; Krebsbach, P. H.; Hollister, S. J. Indirect solid free form fabrication of local and global porous, biomimetic and composite 3D polymer-ceramic scaffolds. Biomaterials 2003, 24 (1), 181-194.

(10) Berretta, S.; Davies, R.; Shyng, Y. T.; Wang, Y.; Ghita, O. Fused Deposition Modelling of high temperature polymers: Exploring CNT PEEK composites. Polym. Test. 2017, 63, 251-262.

(11) Bellehumeur, C.; Li, L.; Sun, Q.; Gu, P. Modeling of Bond Formation Between Polymer Filaments in the Fused Deposition Modeling Process. Journal of Manufacturing Processes 2004, 6 (2), $170-178$.

(12) Song, Y.; Li, Y.; Song, W.; Yee, K.; Lee, K. Y.; Tagarielli, V. L. Measurements of the mechanical response of unidirectional 3Dprinted PLA. Mater. Des. 2017, 123, 154-164.

(13) Zhang, M.; Song, X.; Grove, W.; Hull, E.; Pei, Z. J.; Ning, F.; Cong, W. Carbon Nanotube Reinforced Fused Deposition Modeling Using Microwave Irradiation. ASME, 11th International Manufacturing Science and Engineering Conference; June 27-July 1, 2016; Blacksburg, Virginia, USA, V003T08A007.

(14) Shaffer, S.; Yang, K.; Vargas, J.; Di Prima, M. A.; Voit, W. On reducing anisotropy in $3 \mathrm{D}$ printed polymers via ionizing radiation. Polymer 2014, 55 (23), 5969-5979.

(15) Zaldivar, R. J.; McLouth, T. D.; Patel, D. N.; Severino, J. V.; Kim, H. I. Strengthening of plasma treated 3D printed ABS through epoxy infiltration. Progress in Additive Manufacturing 2017, 2 (4), 193-200.

(16) Compton, B. G.; Lewis, J. A. 3D-Printing of Lightweight Cellular Composites. Adv. Mater. 2014, 26 (34), 5930-5935.

(17) Pierson, H. A.; Celik, E.; Abbott, A.; De Jarnette, H.; Sierra Gutierrez, L.; Johnson, K.; Koerner, H.; Baur, J. W. Mechanical
Properties of Printed Epoxy-Carbon Fiber Composites. Exp. Mech. 2019, 59 (6), 843-857.

(18) Sun, H.; Kim, Y.; Kim, Y. C.; Park, I. K.; Suhr, J.; Byun, D.; Choi, H. R.; Kuk, K.; Baek, O. H.; Jung, Y. K.; Choi, H. J.; Kim, K. J.; Nam, J. D. Self-standing and shape-memorable UV-curing epoxy polymers for three-dimensional (3D) continuous-filament printing. J. Mater. Chem. C 2018, 6 (12), 2996-3003.

(19) Ming, Y.; Zhang, S.; Han, W.; Wang, B.; Duan, Y.; Xiao, H. Investigation on process parameters of $3 \mathrm{D}$ printed continuous carbon fiber-reinforced thermosetting epoxy composites. Additive Manufacturing 2020, 33, 101184.

(20) Ming, Y.; Duan, Y.; Wang, B.; Xiao, H.; Zhang, X. A novel route to fabricate high-performance $3 \mathrm{D}$ printed continuous fiber-reinforced thermosetting polymer composites. Materials 2019, 12 (9), 1369.

(21) Angelopoulos, P. M.; Samouhos, M.; Taxiarchou, M. Functional fillers in composite filaments for fused filament fabrication; a review. Materials Today: Proceedings 2020. DOI: 10.1016/ j.matpr.2020.07.069

(22) Goyanes, A.; Allahham, N.; Trenfield, S. J.; Stoyanov, E.; Gaisford, S.; Basit, A. W. Direct powder extrusion 3D printing: Fabrication of drug products using a novel single-step process. Int. J. Pharm. 2019, 567, 118471.

(23) Yoo, S. H.; Han, M. G.; Hong, J. H.; Chang, S. H. Simulation of curing process of carbon/epoxy composite during autoclave degassing molding by considering phase changes of epoxy resin. Composites, Part B 2015, 77, 257-267.

(24) Zhang, W.; Cotton, C.; Sun, J.; Heider, D.; Gu, B.; Sun, B.; Chou, T. W. Interfacial bonding strength of short carbon fiber/ acrylonitrile-butadiene-styrene composites fabricated by fused deposition modeling. Composites, Part B 2018, 137, 51-59.

(25) Compton, B. G.; Hmeidat, N. S.; Pack, R. C.; Heres, M. F.; Sangoro, J. R. Electrical and Mechanical Properties of 3D-Printed Graphene-Reinforced Epoxy. JOM 2018, 70 (3), 292-297.

(26) Hmeidat, N. S.; Kemp, J. W.; Compton, B. G. High-strength epoxy nanocomposites for 3D printing. Compos. Sci. Technol. 2018, $160,9-20$.

(27) Grejtak, T.; Jia, X.; Cunniffe, A. R.; Shi, Y.; Babuska, T. F.; Pack, R. C.; Vermaak, N.; Compton, B. G.; Krick, B. A. Whisker orientation controls wear of 3D-printed epoxy nanocomposites. Additive Manufacturing 2020, 36, 101515.

(28) Kuang, X.; Zhao, Z.; Chen, K.; Fang, D.; Kang, G.; Qi, H. J. High-Speed 3D Printing of High-Performance Thermosetting Polymers via Two-Stage Curing. Macromol. Rapid Commun. 2018, 39 (7), 1700809.

(29) Lewicki, J. P.; Rodriguez, J. N.; Zhu, C.; Worsley, M. A.; Wu, A. S.; Kanarska, Y.; Horn, J. D.; Duoss, E. B.; Ortega, J. M.; Elmer, W.; Hensleigh, R.; Fellini, R. A.; King, M. J. 3D-Printing of Mesostructurally Ordered Carbon Fiber/Polymer Composites with Unprecedented Orthotropic Physical Properties. Sci. Rep. 2017, 7 (1), 43401 . 